\title{
Surgical treatment of atlantoaxial subluxation by intraoperative skull traction and $\mathrm{C} 1-\mathrm{C} 2$ fixation
}

Jianwei Guo ${ }^{1 \dagger}$, Wencan $\mathrm{Lu}^{2 \dagger}$, Xiangli $\mathrm{Ji}^{3}$, Xianfeng Ren', Xiaojie Tang ${ }^{4}$, Zheng Zhao ${ }^{1}$, Huiqiang Hu${ }^{1}$, Tao Song ${ }^{1}$, Yukun Du${ }^{1}$, Jianyi $\mathrm{Li}^{1}$, Cheng Shao ${ }^{1}$, Tongshuai $\mathrm{Xu}^{1}$ and Yongming $\mathrm{Xi}^{\mathrm{*}}{ }^{*}$

\begin{abstract}
Background: Atlantoaxial subluxation (AAS) is a not rare abnormality between the atlas (C1) and axis (C2). For AAS patients with persistent neck pain and neurologic symptoms, surgical intervention is a good choice. Nevertheless, there were still few reports about the use of intraoperative skull traction and different fixation methods in treatment of AAS.
\end{abstract}

Methods: From January 2012 to December 2018, a total of 86 cases were admitted to our hospital and diagnosed as AAS. All the patients received atlantoaxial reduction with the help of intraoperative skull traction and C1-C2 fixation. Clinical and radiological parameters were collected through chart review.

Results: There were 86 cases included in this study. The mean operative time was $153.9 \pm 73.9 \mathrm{~min}$, and the mean amount of intraoperative blood loss was $219.1 \pm 195.6 \mathrm{ml}$. 81 patients underwent posterior reduction, internal fixation and fusion. 5 patients underwent anterior release, followed by posterior internal fixation and fusion. 82 patients got satisfactory postoperative outcomes while complications occurred in 4 patients. Significant neurologic improvement was observed in these patients. Bone fusion was achieved on the midline sagittal reconstructed CT images at the latest follow-up in all these patients except 1 case. All the patients were followed up for $34.84 \pm$ 15.86 months at average (range 12-60 months). The mean ADI value was $7.55 \pm 1.67 \mathrm{~mm}$ at average preoperatively, and improved to $4.03 \pm 1.21 \mathrm{~mm}$ postoperatively, and to $4.21 \pm 0.99 \mathrm{~mm}$ at the latest follow-up. The mean A-A angle was $15.48 \pm 9.82$ degrees at average preoperatively, and improved to $21.61 \pm 10.43$ degrees postoperatively, and to $19.73 \pm 8.13$ degrees at the latest follow-up. The mean A-A height was $35.61 \pm 7.66 \mathrm{~mm}$ at average preoperatively, and improved to $40.08 \pm 8.5 \mathrm{~mm}$ postoperatively, and to $38.83 \pm 6.97 \mathrm{~mm}$ at the latest follow-up. There were complications in 4 patients, including pedicle misplacement, pedicle screw fracture, infection and one death.

Conclusion: Intraoperative skull traction can effectively facilitate the surgical procedures for ASS caused by different etiologies. Further research will be needed to investigate the safety and effectiveness of this method in the future.

Keywords: Atlantoaxial subluxation, Reduction, Skull traction, General anesthesia

\footnotetext{
* Correspondence: xym700118@163.com

† Jianwei Guo and Wencan Lu contributed equally to this work.

'Department of Orthopedics, The Affiliated Hospital of Qingdao University,

16 Jiangsu Road, Qingdao 266003, Shandong Province, People's Republic of

China

Full list of author information is available at the end of the article
}

(c) The Author(s). 2020 Open Access This article is licensed under a Creative Commons Attribution 4.0 International License, which permits use, sharing, adaptation, distribution and reproduction in any medium or format, as long as you give appropriate credit to the original author(s) and the source, provide a link to the Creative Commons licence, and indicate if changes were made. The images or other third party material in this article are included in the article's Creative Commons licence, unless indicated otherwise in a credit line to the material. If material is not included in the article's Creative Commons licence and your intended use is not permitted by statutory regulation or exceeds the permitted use, you will need to obtain permission directly from the copyright holder. To view a copy of this licence, visit http://creativecommons.org/licenses/by/4.0/ The Creative Commons Public Domain Dedication waiver (http://creativecommons.org/publicdomain/zero/1.0/) applies to the data made available in this article, unless otherwise stated in a credit line to the data. 


\section{Background}

Atlantoaxial subluxation (AAS) is a not rare abnormality between the atlas $(\mathrm{C} 1)$ and axis (C2). Several diseases have been reported to be associated with the occurrence and development of AAS, including inflammatory, congenital, traumatic, and neoplastic processes [1,2]. These processes can damage the zygopophysis joint or ligament between the atlas $(\mathrm{C} 1)$ and axis $(\mathrm{C} 2)$, and cause excessive movement and instability at this junction, resulting in atlantoaxial subluxation. It can cause neck pain and spinal cord compression, even irreversible neurological deficits, such as cervical myelopathy, paresis, respiratory dysfunction, and even consequent death [3]. Early diagnosis and appropriate treatment should be done for this kind of abnormity.

For AAS patients with persistent neck pain and neurologic symptoms, surgical intervention is a good choice. Multiple procedures have been used to stabilize the atlantoaxial joints and achieve spinal cord decompression. These procedures were performed by fixation between $\mathrm{C} 1$ and $\mathrm{C} 2$ at either a lateral mass [4], a pedicle [5], a lamina of C2 [6], or transarticular screws [7]. These procedures have been reported to achieve good surgical outcome and radiological improvement in earlier reports. Besides, intraoperative skull traction has been proved to be a useful method in the reduction of AAS. Nevertheless, there were still few reports about the use of intraoperative skull traction and different fixation methods in treatment of AAS. Therefore, we conduct this study to evaluate the surgical outcomes and radiological improvement of AAS by using intraoperative skull traction and different fixation methods.

\section{Methods}

\section{Patients}

This study was approved by our hospital's ethics committee. From January 2012 to December 2018, a total of 86 cases were admitted to our hospital and diagnosed as AAS. Among them, 53 cases were males and 33 cases were females, with the average age of $52.8 \pm 14.3$ years (17-83 years). All the patients met the following criteria: 1) complaint of neck pain and varying degrees of neurological defects; 2) radiological findings confirm the presence of AAS and spinal cord compression; 3) all the patients received intraoperative skull traction and atlantoaxial reduction and fixation; 4) all the patients got at least 1 - year regular follow-up. Patients without intact follow-up data or follow-up time $<1$ year or with atlantoaxial tumor or infection were excluded.

All the patients received cervical posteroanterior and lateral radiography, dynamic lateral radiography, threedimensional CT, computed tomography angiography (CTA) of cervical arteries, and magnetic resonance imaging (MRI) of the cervical spine. The sex, age, pathology, operative time, blood loss, follow-up time and complications were collected in Table 1 through chart review.

\section{Surgical procedure}

After general anesthesia, all the patients were placed in the supine position. Gardner-Wells tongs traction was performed to observe the reduction of AAS (Fig. 1). The initial traction was performed from $3 \mathrm{~kg}$ for $3 \mathrm{~min}$, the traction weight would increase in accordance with the reduction of AAS, but no more than one-sixth to onefifth of the patient's weight. Somatosensory evoked potentials (SEPs) were used to monitor the neurologic signal throughout the traction procedure. Once the anatomic reduction was achieved, or further reduction could not be achieved with the maximum traction weight applied for $15 \mathrm{~min}$, or abnormal SEPs were observed during traction, the traction procedure was terminated [8].

81 cases achieved satisfactory reduction of AAS, and posterior-only $\mathrm{C} 1-\mathrm{C} 2$ internal fixation and fusion were performed (Fig. 2). These patients were turned into the prone position with the skull traction. The occipital squama, the posterior edge of the occipital foramen, the $\mathrm{C} 1-\mathrm{C} 3$ spinous process, and the lateral mass were exposed via a posterior approach. C1 lateral mass screws and $\mathrm{C} 2$ pedicle screws or laminae screws were implanted according to the $\mathrm{C} 2$ pedicle and HRVA. Two rods were bent to achieve suitable curve and were used to connect the screws at the same side. The $\mathrm{C} 2$ screw heads were tightened firstly, and then the $\mathrm{C} 1$ screw heads were tightened. If $\mathrm{C} 1$ screw heads could not be connected, the C1 spinous process would be lifted up or the C2 spinous process would be pressed downwards. And then all the screws were tightened. The cortical bone at C1-2 was

\begin{tabular}{ll} 
Table 1 Patient demographic and clinical data & \\
\hline Demographics & $33 / 53$ \\
\hline Sex (Femal/Male) & $52.8 \pm 14.3$ \\
Age (Years) & \\
Pathology & 9 \\
Rheumatoid arthritis & 3 \\
Basilar invagination (BI) & 5 \\
Old odontoid fractures & 11 \\
Os odontoideum & 27 \\
Acute cervical trauma & 33 \\
No specific reasons & $153.9 \pm 73.9$ \\
Operative time (min) & $219.1 \pm 195.6$ \\
Blood loss (mL) & $34.84 \pm 15.86$ \\
Follow-up (months) & 4 \\
Complications & \\
\hline
\end{tabular}




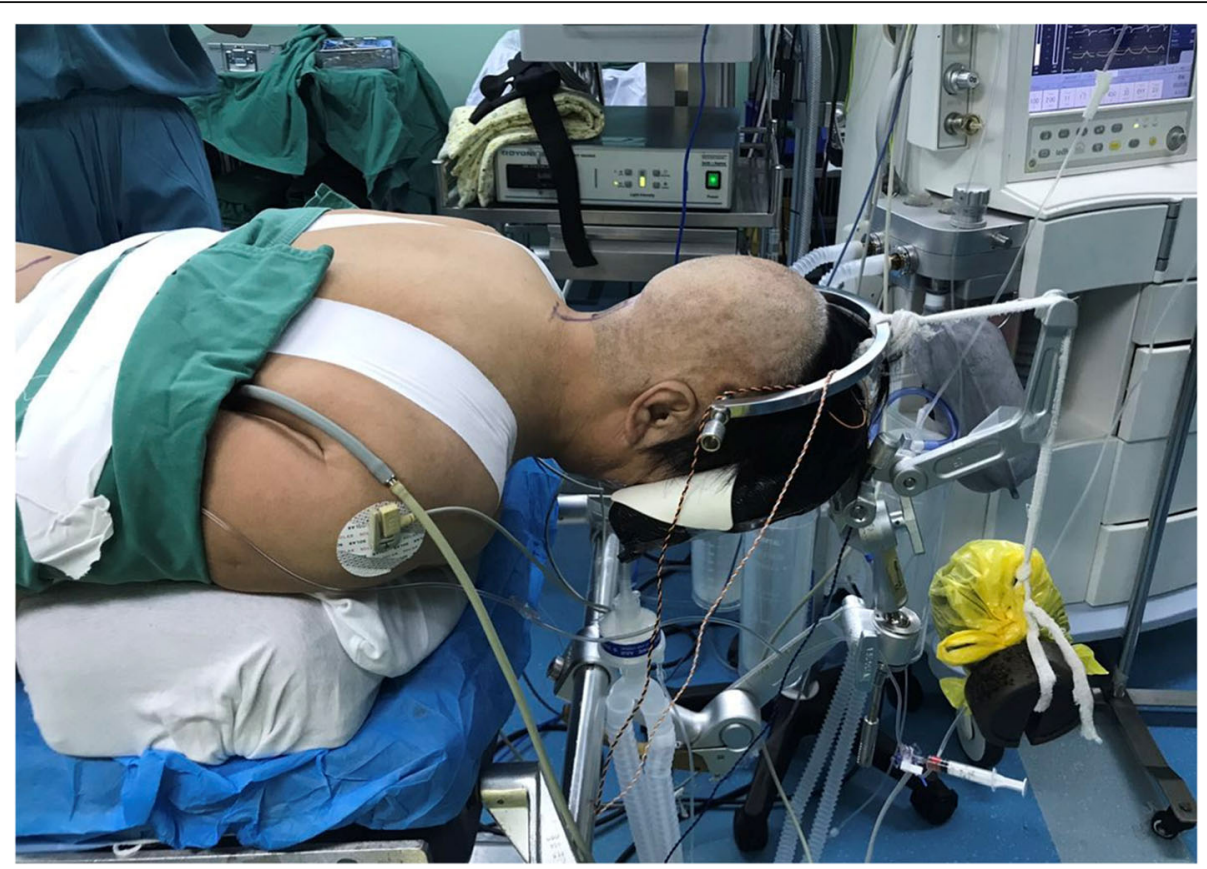

Fig. 1 The patient was placed in the supine position. Gardner-Wells tongs traction was performed to observe the reduction of AAS. The initial traction was performed from $3 \mathrm{~kg}$ for $3 \mathrm{~min}$, the traction weight would increase in accordance with the reduction of AAS, but no more than onesixth to one-fifth of the patient's weight

removed to achieve the bone graft bed, and the iliac or allogenic cancellous bone was grafted finally.

In 5 cases, satisfactory reduction could not be achieved, anterior release surgery and posterior $\mathrm{C} 1-\mathrm{C} 2$ internal fixation and fusion were needed. The patients were placed in a supine position with continuous traction, and the head was placed in an extended position. After oral and nasal mucosal disinfection with iodine, a latex tube was inserted through the nose for posterosuperior traction of the soft palate and uvula. The anterior atlas arch and the lateral mass joints were exposed, and then the osteophytes and scar tissue between the lateral mass joints and the atlanto-odontoid gaps were removed. After that, satisfactory reduction was achieved under the C-arm X-ray examination. These patients were turned into the prone position with the skull traction and then they were subjected to posterior fixation and fusion.

For patients with posterior-only fixation and fusion, the drainage tube was removed within 2-3 days after the operation, and then they could get up and move around 3-5 days after the operation with the help of collar. The collar was needed to restrict the movement of the craniovertebral junction (CVJ) for at least 2-3 months. For patients with transoral anterior release combined with posterior reduction and fusion, they were needed to be monitored in the intensive care unit for $2-3$ days until they were extubated and then transferred to the in-patient ward.

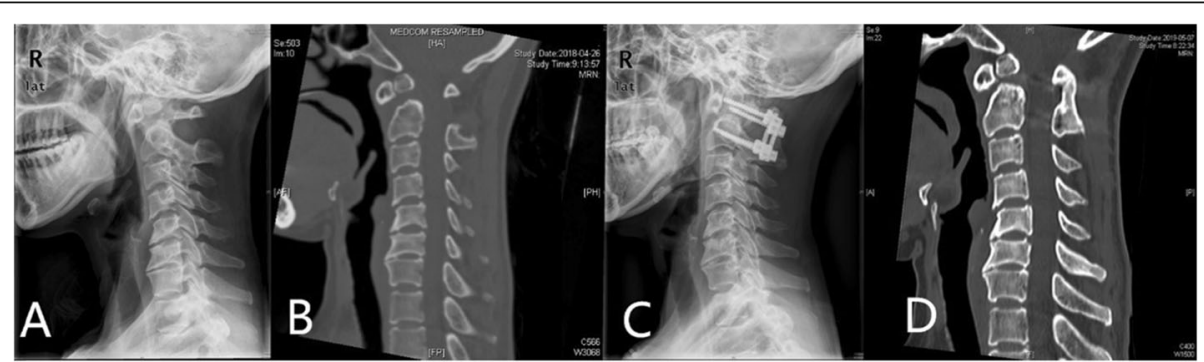

Fig. 2 A 48-year old female suffered from progressive numbness and weakness in the left upper limb for 1 years. Sagittal X-ray (a) and sagittal reconstructed CT images of the cervical spine (b) showed os odontoideum and subluxation at the atlanto-axial joint. Posterior atlantoaxial reduction, fixation and bone graft fusion with intraoperative skull traction under general anesthesia were performed. Satisfactory reduction and fixation were achieved after surgery (c). Sagittal reconstructed CT images of the cervical spine (d) at 1-year follow-up confirmed good fusion at the atlanto-axial joint 
Postoperative cervical X-ray and CT scan were performed to evaluate the fixation and reduction at 1 week after the operation and every follow-up. Follow-up were needed at 3-month, 6-month, 1-year after the surgery and then at yearly intervals. Bony fusion was evaluated at the latest follow-up by cervical CT scan. Radiographic parameters preoperatively, postoperatively and at the latest follow-up, including atlas-dens interval (ADI), atlantoaxial height (A-A height), and atlantoaxial angle (A-A angle, the $\mathrm{C} 1-\mathrm{C} 2$ angle) (Fig. 3) were measured on midline sagittal reconstructed CT images or on a lateralview plain radiograph $[9,10]$. Atlas-dens interval (ADI) was the distance between the posterior margins of the anterior arches of the $\mathrm{C} 1$ vertebra and the anterior margin of Odontoid process. Atlantoaxial angle (A-A angle, the $\mathrm{C} 1-\mathrm{C} 2$ angle) was the angle between the line connecting the lower margins of the anterior and posterior arches of the $\mathrm{C} 1$ vertebra and the lower margin of the C2 vertebra. Atlantoaxial height (A-A height) was the distance between the upper margin of the anterior arch of the $\mathrm{C} 1$ vertebra and the lower margin of the $\mathrm{C} 2$ vertebral body. The Japan Orthopedic Association (JOA) scores were needed to assess the clinical outcome improvement.

\section{Statistical analysis}

Clinical data were presented as mean $\pm \mathrm{SD}$, and analyzed with IBM SPSS Statistics Version 22.0 (IBM Corp, Armonk, New York, USA). ADI, A-A height, and A-A angle preoperatively and postoperatively, postoperatively and at the latest follow-up were compared using the student's paired $t$ test. The $t$-test was used for the comparison and analysis of JOA scores preoperatively and at the latest follow-up. $P<0.05$ was considered statistically significant.

\section{Results}

There were 86 cases included in this study. With respect to the etiology, there were 9 cases with rheumatoid arthritis, 3 cases with basilar invagination (BI), 5 cases with old odontoid fractures, 11 cases with os odontoideum, 27 cases with acute cervical trauma, and 33 cases with no specific reasons. Preoperative cervical threedimensional $\mathrm{CT}$ revealed occiput $(\mathrm{C} 0)-\mathrm{C} 1$ fusion in 6 case and Os odontoideum in 11 cases. In these cases, high-riding vertebral artery (HRVA) were found in 3 patients, and 1 patient had bilateral HRVA.

Eighty one patients underwent posterior reduction, internal fixation and fusion. 5 patients underwent anterior release, followed by posterior internal fixation and fusion. The mean operative time was $153.9 \pm 73.9 \mathrm{~min}$ (range 60-385 $\mathrm{min}$ ), and the mean amount of intraoperative blood loss was $219.1 \pm 195.6 \mathrm{~mL}$ (range 100-1000 $\mathrm{mL}) .82$ patients got satisfactory postoperative outcomes. Significant neurologic improvement was observed in these patients. Bone fusion was achieved on the midline sagittal reconstructed CT images at the latest follow-up in all these patients except 1 case. All the patients were followed up for $34.84 \pm 15.86$ months at average (range 12-60 months). The mean ADI value was $7.55 \pm 1.67$ $\mathrm{mm}$ at average preoperatively, and improved to $4.03 \pm$ $1.21 \mathrm{~mm}$ postoperatively, and to $4.21 \pm 0.99 \mathrm{~mm}$ at the latest follow-up. The mean A-A angle was $15.48 \pm 9.82$ degrees at average preoperatively, and improved to $21.61 \pm 10.43$ degrees postoperatively, and to $19.73 \pm 8.13$ degrees at the latest follow-up. The mean A-A height was $35.61 \pm 7.66 \mathrm{~mm}$ at average preoperatively, and improved to $40.08 \pm 8.5 \mathrm{~mm}$ postoperatively, and to $38.83 \pm 6.97 \mathrm{~mm}$ at the latest follow-up. What's more, the JOA score were $9.6 \pm 3.8$ preoperatively, and improved to $13.4 \pm 3.5$ at the latest follow-up, with

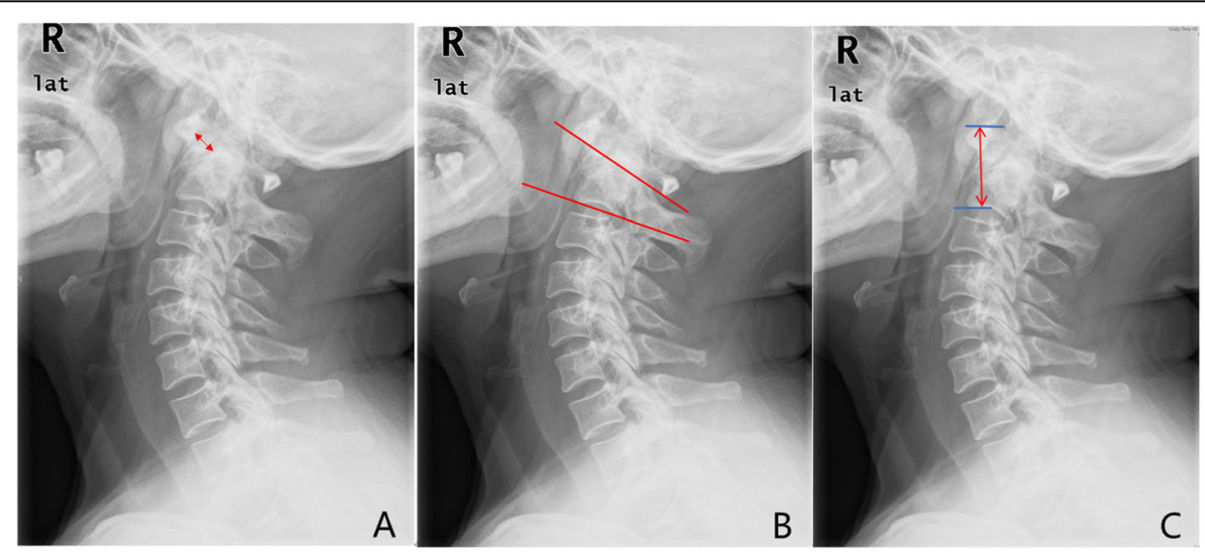

Fig. 3 Radiographic parameters. a Atlas-dens interval (ADI): the distance between the posterior margins of the anterior arches of the C1 vertebra and the anterior margin of Odontoid process. $\mathbf{b}$ Atlantoaxial angle (A-A angle, the C1-C2 angle): the angle between the line connecting the lower margins of the anterior and posterior arches of the C1 vertebra and the lower margin of the C2 vertebra. c Atlantoaxial height (A-A height): the distance between the upper margin of the anterior arch of the C1 vertebra and the lower margin of the C2 vertebral body 
significant statistical differences. There were significant differences between preoperative and postoperative in the ADI, A-A angle, and A-A height, no significant differences between postoperative and the latest follow-up (Table 2).

There were complications in 4 patients. In one patient, $\mathrm{C} 2$ pedicle screw misplacement was found on postoperative cervical CT. However, no abnormal symptoms were observed and no revision surgery was done during longterm follow-ups. One patient had breakage of pedicle screw at 4-month after surgery, which needed revision surgery. One patient developed infection after anterior release surgery, and needed repeated wound debridement. One patient died of acute brainstem infarction at two days after surgery.

\section{Discussion}

In our study, we retrospectively investigated clinical outcomes of AAS using different fixation methods with the help of intraoperative skull traction. Skull traction has been widely used for cervical bone fracture, scoliosis correction, the reduction of AAS and et al. Skull traction under general anesthesia, in which the utility of neuromuscular blockade can remove the tension of cervical muscle and ligaments and make the reduction easier. Wang et al. reported the utility of skull traction under general anesthesia in the reduction of AAS. 904 cases were included in their study [2]. Among those 904 cases, 160 cases did not achieve complete reduction on extension radiograph, but were able to be completely reduced following a short-duration of skull traction under general anesthesia [2]. They believed that dynamic radiographs could not reliably reflect reducibility of AAS, but skull traction under general anesthesia could [2]. This method can achieve anatomical reduction through application of substantial traction with total muscle curarization eliminating any muscular resistance under general anesthesia. Dahdaleh et al. previously reported that the utility of neuromuscular blockade and intraoperative traction could overcome the counteractive retractions of the neck muscles and thus facilitated reduction of $\mathrm{BI}$

Table 2 Radiological results

\begin{tabular}{llll}
\hline & Pre-operative & Post-operative & Latest follow-up \\
\hline ADI (mm) & $7.55 \pm 1.67$ & $4.03 \pm 1.21^{* 1}$ & $4.21 \pm 0.99^{\dagger 1}$ \\
A-A angle (degrees) & $15.48 \pm 9.82$ & $21.61 \pm 10.43^{* 2}$ & $19.73 \pm 8.13^{\dagger 2}$ \\
A-A height (mm) & $35.61 \pm 7.66$ & $40.08 \pm 8.50^{* 3}$ & $38.83 \pm 6.97^{\dagger 3}$ \\
\hline
\end{tabular}

$A D I$ atlas-dens interval, $A-A$ angle atlantoaxial angle, $A-A$ height atlantoaxial height

* Paired $t$ test between pre-operative and post-operative. Significant differences were considered for $P$ value less than $0.05 .{ }^{* 1} P=0.000$,

${ }^{* 2} \mathrm{P}=0.010,{ }^{* 3} \mathrm{P}=0.004$

† Paired $t$ test between post-operative and final follow-up. Significant differences were considered for $P$ value less than $0.05 .{ }^{+1} P=0.079$,

${ }^{+2} \mathrm{P}=0.292,{ }^{+3} \mathrm{P}=0.224$ and chronic atlantoaxial rotatory subluxation in pediatric cases [11, 12]. However, skull traction cannot achieve good results in the absence of general anesthesia. Salunke et al. performed conscious cervical traction in their 57 pediatric IAAD patients, but reduction was achieved in only one patient [13]. Kumar carried out conscious cervical traction in 23 children with congenital atlantoaxial dislocation (AAD) with no patient achieving anatomical reduction [14]. In our cases, 81 cases showed satisfactory reduction and 5 cases showed no reduction with the use of intraoperative dynamic imaging and skull traction under general anesthesia. Besides, the maximum of traction weight should be no more than one-sixth to one-fifth of the patient's body weight. Although skull traction have been believed to be safe under general anesthesia $[2,8]$, SEPs should be used to monitor neurologic signals.

For AAS without good reduction with the utility of skull traction under general anesthesia, sufficient release of the dislocated atlantoaxial joint is of key importance for successful treatment. In order to achieve good reduction, various methods had been used for IAAD patients, including transoral odontoidectomy and posterior fixation [15], transoral atlantoaxial reduction plate internal fixation $[16,17]$, transoral atlantoaxial release and posterior internal fixation [18, 19], and anterior submandibular retropharyngeal approach and posterior internal fixation [20]. All these procedures had advantages and disadvantages. Transoral approach can directly release the tight structures around the atlantoaxial joint and even remove the abnormal odontoid compressing the dural sac, which can assist posterior distractionreduction technique and restore the cranio-cervical anatomy. However, the transoral approach has a high risk of infection $[15,21]$. The anterior submandibular retropharyngeal approach is entirely extraoral and extramucosal, which reduces the rate of infection, while it may be difficult for patients with a big body habitus and short neck [20]. In our present study, the anterior release and posterior reduction and internal fixation were performed in 5 AAS patients without good reduction. After anterior atlantoaxial release procedures, good postoperative reduction results were achieved while complications occurred in two of these 5 AAS patients, including one with infection after anterior release surgery and one died of acute brainstem infarction.

The association between the fixation of atlanto-axis and the effect on the alignment of the subaxial cervical spine have attracted people's attention recently. Yoshimoto $\mathrm{H}$ et al. found that when the A-A angle was fixed in an overextended position, the subaxial alignment would correspond to the overextended A-A angle and become kyphotic [22]. Wang et al. have reported that AAD can influence the alignment of the subaxial cervical 
spine, and achievement of anatomic alignment after the fixation of AAD will allow restoration of the global balance of the cervical spine [2,23]. When the lower margins of the anterior and posterior arches of the $\mathrm{C} 1$ vertebra and the lower margin of the vertebral body of C2 runs almost parallel, the A-A angle is about $30^{\circ}$ [24]. When the $\mathrm{A}-\mathrm{A}$ angle is more than $30^{\circ}$, the $\mathrm{C} 1-\mathrm{C} 2$ region is overextended and the subaxial will become kyphotic. When the A-A angle is less than $30^{\circ}$, the $\mathrm{C} 1-\mathrm{C} 2$ region is distracted and the subaxial alignment will restore lordosis. In our study, the A-A angle in all the patients were fixed less than $30^{\circ}$. No reoperation related to these problems were required in any patient. A long-term study involving a large number of cases is required to further examine the association between the atlantoaxial fixation angle and the change of subaxial alignment.

This study had several limitations. First, this study was a retrospective investigation and was not a randomized case-control study, which may not achieve a strong conclusion. Second, the sample size included in this study was small and this was a single center retrospective study. Third, the etiologies of patients included were multiple. Most of cases included were caused by odontoid fractures, which might attract more attention and limited the results applied to other cases. What's more, the follow-up time was limited. A longer follow-up, randomized case-control and multi-center study will be needed in the future.

\section{Conclusion}

AAS can cause neck pain and spinal cord compression, even irreversible neurological deficits. Early diagnosis and appropriate treatment should be performed for this kind of abnormity. Intraoperative skull traction can effectively facilitate the surgical procedures for ASS caused by different etiologies. It can not only effectively facilitate the reduction of ASS, but also make the $\mathrm{C} 1$ and $\mathrm{C} 2$ stable and easy to be implanted during the operation. Satisfactory clinical outcomes can be achieved for patients with satisfactory reduction with the help of intraoperative skull traction under general anesthesia. Multicenter research and longer follow-up are needed in the future to investigate the safety and effectiveness of this method.

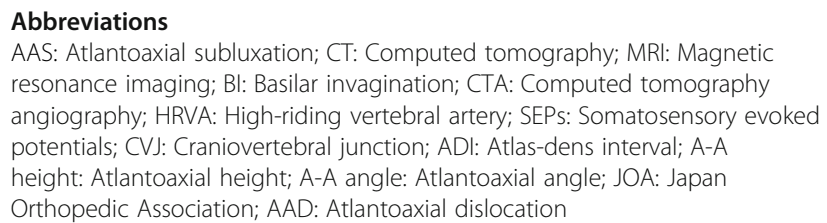

\section{Abbreviations}

AAS: Atlantoaxial subluxation; CT: Computed tomography; MRI: Magnetic resonance imaging; BI: Basilar invagination; CTA: Computed tomography angiography; HRVA: High-riding vertebral artery; SEPs: Somatosensory evoked potentials; CVJ: Craniovertebral junction; ADI: Atlas-dens interval; A-A height: Atlantoaxial height; A-A angle: Atlantoaxial angle; JOA: Japan Orthopedic Association; AAD: Atlantoaxial dislocation

\section{Acknowledgements}

We would like to thank $Y X$ for contribution with revision of the draft, and to thank XJ, XR, XT, ZZ, HH, TS, YD, JL, CS, TX for their contribution of data collection and data handling in the study.

\section{Authors' contributions}

YX designed the study and critically revised the manuscript. JG and WL carried out the statistical analyses, and drafted the manuscript. XJ, XR, XT, ZZ, $H H, T S, Y D, J L, C S, T X$ were responsible for the data collection and measurement of radiographic data. All authors read and approved the final manuscript.

\section{Funding}

This work was supported by Taishan Scholars Program, Shandong province, China (NO.ts20190985), Young and middle-aged teachers project of fujian provincial department of education (JAT170224), Sanming Project of Medicine in Shenzhen (SZSM201911011).

\section{Availability of data and materials}

The data used and analyzed during the current study are available in anonymized form from the corresponding author on reasonable request.

\section{Ethics approval and consent to participate}

This article is designed and submitted acting on guideline of IRB of Affiliated Hospital of Qingdao University and all patients have signed consent forms for this study.

\section{Competing interests}

The authors declare that they have no competing interests. No benefits in any form have been or will be received from a commercial party related directly or indirectly to the subject of this manuscript.

\section{Author details}

${ }^{1}$ Department of Orthopedics, The Affiliated Hospital of Qingdao University, 16 Jiangsu Road, Qingdao 266003, Shandong Province, People's Republic of China. ${ }^{2}$ Department of Spine Surgery, Shenzhen University General Hospital, Xueyuan AVE 1098, Nanshan District, Shenzhen, Guangdong, People's Republic of China. ${ }^{3}$ Department of Intensive Care Unit, Qilu Hospital of Shandong University (Qingdao), 758 Hefei Road, Qingdao 266035, Shandong Province, People's Republic of China. ${ }^{4}$ Department of Orthopedics, Yantai Affiliated Hospital of Binzhou Medical University, 717 Jinbu Street, Muping District, Yantai 264000, Shandong Province, People's Republic of China.

Received: 10 March 2020 Accepted: 7 April 2020

Published online: 14 April 2020

\section{References}

1. Greenberg AD. Atlanto-axial dislocations. Brain. 1968;91:655-84.

2. Wang S, Wang C, Yan M, Zhou H, Dang G. Novel surgical classification and treatment strategy for atlantoaxial dislocations. Spine (Phila Pa 1976). 2013; 38:E1348-56.

3. Yamada T, Matsukura Y, Oyaizu T, Yuasa M, Hirai T, Sakaki K, Inose H, Torigoe I, Sakai K, Okawa A, Arai Y. Retrospective analysis of surgical outcomes for atlantoaxial subluxation. J Orthop Surg Res. 2019;14:75.

4. Tan M, Wang H, Wang Y, Zhang G, Yi P, Li Z, Wei H, Yang F. Morphometric evaluation of screw fixation in atlas via posterior arch and lateral mass. Spine (Phila Pa 1976). 2003;28:888-95.

5. Abumi K, Itoh H, Taneichi H, Kaneda K. Transpedicular screw fixation for traumatic lesions of the middle and lower cervical spine: description of the techniques and preliminary report. J Spinal Disord. 1994;7:19-28.

6. Wright NM. Posterior C2 fixation using bilateral, crossing C2 laminar screws: case series and technical note. J Spinal Disord Tech. 2004;17:158-62.

7. Tokuhashi Y, Matsuzaki H, Shirasaki Y, Tateishi T. C1-C2 intra-articular screw fixation for atlantoaxial posterior stabilization. Spine (Phila Pa 1976). 2000;25: 337-41.

8. Ma F, Kang M, Liao YH, Lee GZ, Tang Q, Tang C, Wang Q, Zhong J. The use of intraoperative traction for achieving reduction of irreducible atlantoaxial dislocation caused by different craniovertebral junction pathologies. Clin Neurol Neurosurg. 2018;175:98-105

9. Behari S, Bhargava V, Nayak S, Kiran Kumar MV, Banerji D, Chhabra DK, Jain VK. Congenital reducible atlantoaxial dislocation: classification and surgical considerations. Acta Neurochir. 2002;144:1165-77.

10. Shuhui G, Jiagang L, Haifeng C, Hao ZB, Qing HS. Surgical Management of Adult Reducible Atlantoaxial Dislocation, basilar invagination and Chiari malformation with Syringomyelia. Turk Neurosurg. 2016;26:615-21. 
11. Dahdaleh NS, Dlouhy BJ, Menezes AH. Application of neuromuscular blockade and intraoperative 3D imaging in the reduction of basilar invagination. J Neurosurg Pediatr. 2012;9:119-24.

12. Dahdaleh NS, Dlouhy BJ, Menezes AH. One-step fixation of atlantoaxial rotatory subluxation: technical note and report of three cases. World Neurosurg. 2013;80:e391-5.

13. Salunke P, Behari S, Kirankumar MV, Sharma MS, Jaiswal AK, Jain VK. Pediatric congenital atlantoaxial dislocation: differences between the irreducible and reducible varieties. J Neurosurg. 2006;104:115-22.

14. Kumar R, Nayak SR. Management of pediatric congenital atlantoaxial dislocation: a report of 23 cases from northern India. Pediatr Neurosurg. 2002;36:197-208.

15. Elbadrawi AM, Elkhateeb TM. Transoral approach for Odontoidectomy efficacy and safety. HSS J. 2017;13:276-81.

16. Yin QS, Ai FZ, Zhang K, Mai XH, Xia H, Wu ZH. Transoral atlantoaxial reduction plate internal fixation for the treatment of irreducible atlantoaxial dislocation: a 2- to 4-year follow-up. Orthop Surg. 2010;2:149-55.

17. Zhang B, Liu H, Cai X, Wang Z, Xu F, Liu X, Wang H, Kang H, Ding R. Biomechanical comparison of modified TARP technique versus modified Goel technique for the treatment of basilar invagination: a finite element analysis. Spine (Phila Pa 1976). 2016;41:E459-66.

18. Wang C, Yan M, Zhou HT, Wang SL, Dang GT. Open reduction of irreducible atlantoaxial dislocation by transoral anterior atlantoaxial release and posterior internal fixation. Spine (Phila Pa 1976). 2006;31:E306-13.

19. Laheri V, Chaudhary K, Rathod A, Bapat M. Anterior transoral atlantoaxial release and posterior instrumented fusion for irreducible congenital basilar invagination. Eur Spine J. 2015;24:2977-85.

20. Ren X, Gao F, Li S, Yang J, Xi Y. Treatment of irreducible atlantoaxial dislocation using one-stage retropharyngeal release and posterior reduction. J Orthop Surg (Hong Kong). 2019;27:2309499019870465.

21. Jones DC, Hayter JP, Vaughan ED, Findlay GF. Oropharyngeal morbidity following transoral approaches to the upper cervical spine. Int J Oral Maxillofac Surg. 1998;27:295-8.

22. Yoshimoto H, Ito M, Abumi K, Kotani Y, Shono Y, Takada T, Minami A. A retrospective radiographic analysis of subaxial sagittal alignment after posterior C1-C2 fusion. Spine (Phila Pa 1976). 2004;29:175-81.

23. Passias PG, Wang S, Kozanek M, Wang S, Wang C. Relationship between the alignment of the occipitoaxial and subaxial cervical spine in patients with congenital atlantoxial dislocations. J Spinal Disord Tech. 2013;26:15-21.

24. Uei H, Tokuhashi Y, Maseda M. Radiographic and clinical outcomes of C1-C2 intra-articular screw fixation in patients with atlantoaxial subluxation. J Orthop Surg Res. 2018;13:273.

\section{Publisher's Note}

Springer Nature remains neutral with regard to jurisdictional claims in published maps and institutional affiliations.

Ready to submit your research? Choose BMC and benefit from:

- fast, convenient online submission

- thorough peer review by experienced researchers in your field

- rapid publication on acceptance

- support for research data, including large and complex data types

- gold Open Access which fosters wider collaboration and increased citations

- maximum visibility for your research: over $100 \mathrm{M}$ website views per year

At $\mathrm{BMC}$, research is always in progress.

Learn more biomedcentral.com/submissions 